\title{
Induction of avidin in the chick oviduct by tissue damage and prostaglandins
}

\author{
P. K. Heinonen, T. Metsä-Ketelä and P. Tuohimaa \\ Department of Biomedical Sciences, University of Tampere, \\ Box 607, SF-33101 Tampere 10, Finland
}

\begin{abstract}
Summary. In immature, diethylstilboestrol-treated chicks, ligation of the oviduct caused local avidin synthesis in the immediate vicinity of the ligature. PGF-2 $\alpha$ injected directly into the oviduct also induced avidin synthesis, whereas saline or PGE-2 had no effect. PGE and PGF-2 $\alpha$ concentrations increased in the oviduct within 24 h of ligation: the PGE increase could be partly inhibited by indomethacin, whereas that of PGF-2 $\alpha$ was less inhibited. An $\mathrm{LD}_{50}$ dose of indomethacin alone and with ligation had a clear stimulatory effect on avidin synthesis, whereas aspirin alone, or with ligation, was not effective. Ligation alone and with indomethacin appeared to alter the PGF-2 $\alpha /$ PGE ratio. These results suggest that PGF-2 $\alpha$ may be involved in the regulation of avidin synthesis in the chick oviduct.
\end{abstract}

\section{Introduction}

Avidin, a secretory protein of the avian oviduct, is induced by progesterone treatment of the immature chick (O'Malley, McGuire, Kohler \& Korenman, 1969) or by several non-specific factors, such as pinching or ligation of the oviduct (Elo, Tuohimaa \& Jänne, 1975). Avidin production is found in the immediate vicinity of the trauma, which indicates that the induction is local (Heinonen \& Tuohimaa, 1976). Trauma and ischaemia are also known to stimulate the synthesis of prostaglandins (PGs) (Ramwell \& Shaw, 1971) and we therefore investigated the effect of ligation on oviductal PGs and the direct effect of PGs and their inhibitors on avidin synthesis.

\section{Materials and Methods}

The experimental animals were Leghorn chicks (strains Ti 53 and Ti 453) supplied by Turun Muna Hatchery, Turku, Finland. Growth of the oviduct was stimulated by 9 daily subcutaneous injections of $0.5 \mathrm{mg}$ diethylstilboestrol (DES) in $0.05 \mathrm{ml}$ sesame oil, beginning on the first or second day after hatching. The chicks were taken for experiments 1 day after the last DES injection and were killed $24 \mathrm{~h}$ later. The animals weighed $70-110 \mathrm{~g}$. The oviduct was ligated when necessary as described by Heinonen \& Tuohimaa (1976).

Experiment 1. Avidin synthesis was examined after intraoviductal administration of PGF-2 $\alpha$ or PGE-2 (Upjohn Company, Kalamazoo, Michigan) dissolved in ethanol and diluted in $0.76 \%(w / v)$ $\mathrm{NaCl}$ solution to give a concentration of $1 \mu \mathrm{g} / \mathrm{ml}$. The control birds were injected similarly with vehicle ('saline') or not at all ('none'). After ether anaesthesia the abdominal layers were dissected, the oviduct was identified and, avoiding mechanical manipulation, PG solution $(30 \mathrm{ng} / 100 \mathrm{~g}$ body weight) was injected into the magnum-isthmus junction of the oviduct. The abdominal layers were sutured and the animals were killed $24 \mathrm{~h}$ later for determination of the avidin concentration by the method of Heinonen \& Tuohimaa (1976).

Experiment 2. The effect of ligation on PG synthesis was studied. The content of PGF-2 $\alpha$ and PGE (total) in the oviducts was determined by radioimmunoassay (see below) 15 min, 1, 3, 6, 10, 12 and $24 \mathrm{~h}$ after ligation. The effect of indomethacin on oviductal PGF-2 $\alpha$ and PGE levels was studied by implanting $25 \mathrm{mg}$ indomethacin subcutaneously $1 \mathrm{~h}$ before the ligation. The birds were again killed $15 \mathrm{~min}, 1,3,6,10,12$ or $24 \mathrm{~h}$ after ligation. The control chicks were neither ligated nor injected with indomethacin. 
Experiment 3. The action of prostaglandin synthetase inhibitors on the induction of avidin synthesis by ligation was investigated. Aspirin (acetylsalicylic acid) was purified and crystallized as described in the Pharmacopoeia Nordica. Animals were divided into 3 groups: (1) $40 \mathrm{mg}$ aspirin/ $100 \mathrm{~g}$ body weight were given subcutaneously $30 \mathrm{~min}$ after the ligation, (2) $50 \mathrm{mg}$ aspirin were given in 5 doses at 4-h intervals, beginning $1 \mathrm{~h}$ before the ligation, (3) $50 \mathrm{mg}$ aspirin were given without ligation. In experiments with indomethacin (Indocid; Merck Sharp \& Dohme, Holland), the birds were divided into 4 groups: (4) $50 \mathrm{mg}$ powdered indomethacin were implanted subcutaneously $1 \mathrm{~h}$ before the ligation, (5) $15 \mathrm{mg}$ crystalline indomethacin were implanted subcutaneously in 5 doses at 4-h intervals, beginning $1 \mathrm{~h}$ before the ligation, (6) $15 \mathrm{mg}$ indomethacin were given intraperitoneally in $10 \mathrm{~mm}$-phosphate buffer, $\mathrm{pH} 7 \cdot 4,30 \mathrm{~min}$ before the ligation, (7) $50 \mathrm{mg}$ indomethacin was implanted subcutaneously without ligation. In Groups 4 and $750 \%$ of the birds died during the experiment. In Group 8 the birds received ligation alone without aspirin or indomethacin. After each chick was killed the oviduct was divided carefully into 4 pieces: shell gland, isthmus, lower part of the magnum (isthmus-magnum) and upper part of the magnum (magnum). The avidin concentration of each part was assayed.

Prostaglandin assay. The oviducts were dissected free of membranes, weighed and frozen in liquid nitrogen. The tissue was homogenized in $4 \mathrm{ml} \mathrm{50 \%} \mathrm{ethanol} \mathrm{(v/v)} \mathrm{with} \mathrm{an} \mathrm{X-1020} \mathrm{homogenizer}$ and PGs were extracted by the method of Unger, Stamford \& Bennett (1971). The PG content was measured by radioimmunoassay with PGF-2 $\alpha$ and PGE kits (Clinical Assays Inc., Cambridge, Massachusetts) as described by Jaffee, Smith, Newton \& Parker (1971). Antigen-antibody complex was separated by the method of Gersham, Powers, Levine \& Van Vunakis (1972). Recoveries were monitored by using labelled PGE-1 (sp. act. $53 \mathrm{Ci} / \mathrm{mmol}$ : Radiochemical Centre, Amersham). The cross-reactivity of the PGF- $2 \alpha$ antiserum was $42 \%$ with PGF- $1 \alpha$ at the $50 \%$ binding level, varying from 15 to $63 \%$ at 15 and $80 \%$ binding levels, respectively, and $<0.02 \%$ with PGE, PGA and PGB. The total PGE concentration was measured as PGB after conversion by treatment with $\mathrm{NaOH}$. The cross-reactivity of the PGB-1 antiserum was very low. To get an equal reduction in counts a 60 times higher concentration of PGE-1 and a 400 times higher concentration of PGE-2 was needed. For an equal reduction in counts with PGF-1 $\alpha$ the concentrations were $10^{4}$ times higher than with PGE-1.

The significance of differences was determined with Student's $t$ test.

\section{Results}

Experiment 1. PGF-2 $\alpha$ had a clear stimulatory effect on oviductal synthesis of avidin, whereas injection of PGE-2 or $\mathrm{NaCl}$ had no significant effect on avidin content (Table 1).

Experiment 2. Table 2 illustrates the effect of ligation, alone and with indomethacin, on PG levels. During the first $3 \mathrm{~h}$ after ligation of the oviduct the content of PGF-2 $\alpha$ was lower than the control level $(2 \cdot 6 \pm 0.5 \mathrm{ng} / \mathrm{g}$ oviduct, $\mathrm{N}=12)$. After $6 \mathrm{~h}, \mathrm{PGF}-2 \alpha$ content had increased to a plateau which lasted at least $24 \mathrm{~h}$. Indomethacin had no effect during the first $6 \mathrm{~h}$, but the value at $24 \mathrm{~h}$ was significantly lower than that after ligation alone. The content of PGE did not fall after ligation (control level $=3.0 \pm 0.5 \mathrm{ng} / \mathrm{g}$ oviduct, $\mathrm{N}=4$ ) and the increase, later than that of PGF- $2 \alpha$, was not

Table 1. The effect of prostaglandin injection (30 $\mathrm{ng} / 100 \mathrm{~g}$ ) into the chick oviduct on avidin concentration (mean \pm s.e.m.)

\begin{tabular}{lcc}
\hline Treatment & No. of birds & $\begin{array}{c}\text { Avidin conc. } \\
(\mu \mathrm{g} / \mathrm{g} \text { oviduct })\end{array}$ \\
\hline None & 4 & $0.1 \pm 0.0$ \\
Saline & 9 & $0.2 \pm 0.1$ \\
PGE-2 & 7 & $0.4 \pm 0.2$ \\
PGF-2 $\alpha$ & 10 & $4 \cdot 3 \pm 1 \cdot 8^{*}$ \\
\hline
\end{tabular}

* Value significantly different $(P<0.05)$ from that 
Table 2. The effect of ligation of the chick oviduct, alone and with indomethacin (ind.), on the PGE and PGF-2 $\alpha$ concentrations (mean \pm s.e.m., nos in parentheses)

\begin{tabular}{|c|c|c|c|c|c|}
\hline \multirow[b]{2}{*}{$\begin{array}{l}\text { Time } \\
\text { (h) }\end{array}$} & \multicolumn{2}{|c|}{ PGF-2 $\alpha(\mathrm{ng} / \mathrm{g})$} & \multicolumn{2}{|c|}{ PGE (ng/g) } & \multirow{2}{*}{$\begin{array}{l}\text { PGF-2 } \alpha: \text { PGE } \\
\text { (ligation } \\
\text { only) }\end{array}$} \\
\hline & Ligation & $\begin{array}{l}\text { Ligation } \\
+ \text { ind. }\end{array}$ & Ligation & $\begin{array}{l}\text { Ligation } \\
\text { + ind. }\end{array}$ & \\
\hline 0.25 & $0.1 \pm 0.0(4)$ & - & $1.6 \pm 0.7(3)$ & - & 0.06 \\
\hline 1 & $1.4 \pm 0.3(4)$ & $0.1 \pm 0.1$ & $4 \cdot 0 \pm 1 \cdot 1(3)$ & $4.0 \pm 0.7$ & 0.35 \\
\hline 3 & $1 \cdot 0 \pm 0.3(4)$ & $2.1 \pm 0.6$ & $2 \cdot 6 \pm 1 \cdot 1(4)$ & $2.5 \pm 0.6$ & 0.39 \\
\hline 6 & $5.8 \pm 1.3(4)$ & $5.6 \pm 1.0$ & $3.5 \pm 0.3(4)$ & $2.9 \pm 0.9$ & 1.66 \\
\hline 10 & $5.3 \pm 1.4(3)$ & $3.5 \pm 1.2$ & $4.4 \pm 1 \cdot 3(3)$ & $2 \cdot 1 \pm 0.3^{*}(4)$ & $1 \cdot 20$ \\
\hline 12 & - & - & $7 \cdot 5 \pm 2 \cdot 1(3)$ & $0.6 \pm 0.5 *(3)$ & - \\
\hline 24 & $5 \cdot 5 \pm 1 \cdot 3(8)$ & $2.5 \pm 0.8^{*}(4)$ & $7 \cdot 1 \pm 1 \cdot 6(4)$ & - & 0.78 \\
\hline
\end{tabular}

* Values significantly different $(P<0.05)$ from those in corresponding birds with ligation alone.

Table 3. The effects of aspirin and indomethacin on the levels (mean \pm s.e.m., $\mu$ g avidin/g oviduct) of ligationinduced avidin in the diethylstilboestrol-primed chick oviduct

\begin{tabular}{|c|c|c|c|c|c|c|}
\hline Group & Treatment & $\begin{array}{l}\text { No. of } \\
\text { birds }\end{array}$ & $\begin{array}{l}\text { Shell } \\
\text { gland }\end{array}$ & Isthmus & $\begin{array}{l}\text { Magnum- } \\
\text { isthmus }\end{array}$ & Magnum \\
\hline 1 & $40 \mathrm{mg}$ aspirin s.c. + ligation & 17 & $0.2 \pm 0.1$ & $2 \cdot 3 \pm 0.7$ & $8 \cdot 6 \pm 1 \cdot 3$ & $0.6 \pm 0.3$ \\
\hline 2 & $5 \times 10 \mathrm{mg}$ aspirin s.c. + ligation & 8 & $0.1 \pm 0.1$ & $2.4 \pm 0.8$ & $8 \cdot 2 \pm 1 \cdot 7$ & $0.8 \pm 0.3$ \\
\hline 3 & $50 \mathrm{mg}$ aspirin s.c. & 5 & 0 & 0 & $\mathbf{0}$ & 0 \\
\hline 4 & $50 \mathrm{mg}$ indomethacin s.c. + ligation & 5 & $3 \cdot 8 \pm 1 \cdot 0^{*}$ & $12 \cdot 0 \pm 3 \cdot 2^{*}$ & $31 \cdot 7 \pm 7 \cdot 4^{*}$ & $18 \cdot 4 \pm 5 \cdot 5^{*}$ \\
\hline 5 & $5 \times 3 \mathrm{mg}$ indomethacin s.c. + ligation & 8 & $0.2+0.1$ & $0.4+0.3$ & $9 \cdot 1+1.6$ & $0.0+0.2$ \\
\hline 6 & $15 \mathrm{mg}$ indomethacin i.p. + ligation & 4 & $2 \cdot 3 \pm 0 \cdot 8$ & $6 \cdot 1 \pm 2 \cdot 7$ & $15 \cdot 6 \pm 2 \cdot 4$ & $3 \cdot 2 \pm 1 \cdot 0$ \\
\hline 7 & $50 \mathrm{mg}$ indomethacin s.c. & 4 & $18 \cdot 7 \pm 2 \cdot 0^{*}$ & $22 \cdot 0 \pm 4 \cdot 0^{*}$ & $17 \cdot 9 \pm 2 \cdot 7 *$ & $23 \cdot 8 \pm 2 \cdot 5 *$ \\
\hline 8 & Ligation only & 30 & $0.2 \pm 0.1$ & $1 \cdot 0 \pm 0.3$ & $7 \cdot 1 \pm 0.8$ & $0.4 \pm 0.1$ \\
\hline
\end{tabular}

* Values significantly different $(P<0.05)$ from those in birds in which the treatment was ligation only (Group 8 ).

significant (Table 2). Indomethacin had clearly inhibited the effect of ligation on PGE levels by $10 \mathrm{~h}$ after ligation. Ligation, alone or with indomethacin, appeared to induce a biphasic change in the ratio of PGF-2 $\alpha$ : PGE concentrations.

Experiment 3. The effects of the two PG synthetase inhibitors, aspirin and indomethacin, on the induction of avidin by ligation are shown in Table 3. Aspirin had no effect on the amount of avidin in either the ligated or the non-ligated oviduct. In contrast, there was a statistically significant induction of avidin when an $\mathrm{LD}_{50}$ dose of indomethacin was given alone or with ligation. In the ligated oviduct the highest avidin content was found close to the ligature.

\section{Discussion}

Our results indicate that PGF-2 $\alpha$ is involved in the induction of avidin secretion by the oviduct. When exogenous PGs are injected directly into the oviduct, PGF-2 $\alpha$, but not PGE, stimulates avidin synthesis. It is possible that PGE may be metabolized much more rapidly than PGF-2 $\alpha$ and so is prevented from having an effect upon avidin production when exogenously administered. The role, if any, of PGE in avidin induction therefore needs more investigation. Ligation of the oviduct appears to enchance the synthesis of both PGs, although the details of the effect differed (see Table 2). The changes in ratio of the two PGs occur during the critical time when avidin synthesis begins (Elo et al., 1975). Because exogenous PGF-2 $\alpha$, but not PGE, induces avidin synthesis, we propose that the PGF- $2 \alpha$ dominance between 3 and $6 \mathrm{~h}$ after ligation is important in the induction of avidin.

Since ligation increases PGs and PGF-2 $\alpha$ can induce avidin, it is surprising that the induction of avidin by ligation cannot be inhibited even by very high doses of indomethacin or aspirin. Indeed, toxic levels of indomethacin result in avidin synthesis, not only att the site of ligature, bue also else- $-1: 19: 38 \mathrm{AM}$ 
where in the oviduct. However, the ligation-induced PGF-2 $\alpha$ synthesis could not be inhibited by an $\mathbf{L D}_{50}$ dose of indomethacin. This indicates that the avian oviduct may be unresponsive to indomethacin, because much smaller doses of this drug affect the PGs in mammalian tissues (Vane, 1971). Therefore, the inability of indomethacin and aspirin to inhibit avidin induction by ligation may be explained by a lack of effect on PGs. The stimulatory effect of a high dose of indomethacin, which inhibits the increase in PGE after ligation, could result from a lack of effect on PGF-2 $\alpha$ levels, i.e. administration of a toxic dose of indomethacin still allows the appearance, and perhaps even the intensification, of a PGF-2 $\alpha$ dominance between 3 and $6 \mathrm{~h}$ after ligation. The induction of high levels of avidin in all parts of the oviduct after $50 \mathrm{mg}$ indomethacin and ligation, but only in the immediate vicinity after ligation alone, suggests that PGF- $2 \alpha$ dominance might even be caused by the indomethacin itself, whose effects on PGs would be expected to occur throughout the oviduct after such exogenous administration. This possibility is supported by the induction of avidin synthesis throughout the oviduct by a high dose of indomethacin alone. This dose was, however, an LD $_{50}$ dose and may have affected avidin in an entirely non-specific fashion. The possibility that the effect of indomethacin on avidin induction may be via alterations in PG levels therefore requires further study.

It has been suggested that the ovum causes PG synthesis by distending the oviduct and that the higher levels of PGs cause increased oviduct motility (Talo \& Kekäläinen, 1976). This increased motility might then further enhance PG synthesis in the form of a positive feedback mechanism. The sensitivity of hen oviductal tissue to PGs supports this hypothesis (Wechsung \& Houvenaghel, 1976). Our earlier experiments indicate that trauma (ligation or pinching) of the oviduct plays a role in the synthesis and secretion of avidin (Elo et al., 1975; Heinonen \& Tuohimaa, 1976). Our present results show that, since exogenous PGF-2 $\alpha$ stimulates avidin secretion and ligation increases PGs, the ligation effect on avidin production may be mediated by PGs. Perhaps the reported effect of distension of the oviduct by an ovum on PGs may also therefore result in the induction of avidin secretion. This hypothesis is supported by the presence of avidin in the avian egg (Hertz \& Sebrell, 1942).

We are indebted to Dr Trevor Wigham for critical suggestions and Mrs Arja Ahola and Mrs Outi Kurronen for their technical assistance. This work was supported by grant No. 760-0526 from the Ford Foundation. The prostaglandins were kindly supplied by Dr J. E. Pike of Upjohn Company, Kalamazoo, Michigan, U.S.A.

\section{References}

Elo, H., TuohimaA, P. \& JänNe, O. (1975) Cumulative superinduction of avidin in the chick oviduct by tissue damage and actinomycin D. Molec, cell. Endocr. 2, 203-211.

Gersham, H., Powers, E., Levine, L. \& Van Vunakis, H. (1972) Radioimmunoassay of prostaglandins, angiotensin, digoxin and adenosine- $3^{\prime}, 5^{\prime}$-cyclicmonophosphate with nitrocellulose membranes. Prostaglandins 1, 407-423.

Heinonen, P.K. \& TuohimaA, P. (1976) Induction of avidin in the chick oviduct by tissue damage. Effect of promethazine chloride, $\mathrm{CaCl}_{2}$ and hydrocortisone on local induction. Molec. cell. Endocr. 5, 209-214.

Hertz, R. \& Sebrell, W.E. (1942) Occurrence of avidin in the oviduct and secretions of the genital tract of several species. Science, N.Y. 92, 257-258.

Jaffee, B.M., Smith, J.W., Newton, W.T. \& Parker, C.W. (1971) Radioimmunoassay for prostaglandins. Science, N.Y. 171, 494-496.
O'Malley, B.W., McGuire, W.L., Kohler, P.O. \& Korenman, S.G. (1969) Studies on the mechanism of steroid hormone regulation of synthesis of specific proteins. Recent Prog. Horm. Res. 25, 105-160.

Ramwell, P.W. \& SHAW, J.E. (1971) The biological significance of the prostaglandins. Ann. N.Y. Acad. Sci. 180, 10-13.

Talo, A. \& KeKÄL̈INen, R. (1976) Ovum promotes its own transport in the oviduct of the Japanese quail. Biol. Reprod. 14, 186-189.

UNGer, G.W., STAMFord, I.F. \& BenNetr, A. (1971) Extraction of prostaglandins from human blood. Nature, Lond. 233, 336-337.

VANE, J.R. (1971) Inhibition of prostaglandin synthesis as a mechanism of action for aspirin-like drugs. Nature, New Biol. 231, 232-235.

Wechsung, E. \& Houvenaghel, A. (1976) A possible role of prostaglandins in the regulation of ovum transport and oviposition in the domestic hen? Prostaglandins 12, 599-608. 